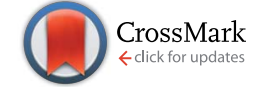

Cite this: RSC Adv., 2017, 7, 7718
Received 3rd November 2016 Accepted 11th January 2017

DOI: $10.1039 / c 6 r a 26249 j$

www.rsc.org/advances

\section{Morphology evolution of Ag/Au nanocomposites via temperature-controlled galvanic exchange to enhance catalytic activity $\dagger$}

\begin{abstract}
Tae-Hyeon Park, Hyeri Lee, Jaewon Lee and Du-Jeon Jang*
Morphology-controlled $\mathrm{Ag} / \mathrm{Au}$ nanocomposites have been fabricated facilely via a modified galvanic replacement reaction using $\mathrm{Ag}$ nanocubes as sacrificial templates. The structures of the $\mathrm{Ag} / \mathrm{Au}$ nanocomposites produced at the galvanic reaction temperatures of $0,25,55,85$, and $105^{\circ} \mathrm{C}$ were found to be Au-decorated Ag nanocubes, well-defined nanoboxes, truncated nanoboxes, porous nanoboxes, and broken nanoboxes, respectively. Compared to pristine $\mathrm{Ag}$ nanocubes or $\mathrm{Ag} / \mathrm{Au}$ nanocomposites without cavities, Ag/Au nanocatalysts with hollow interiors have been found to catalyze the reduction of rhodamine $\mathrm{B}$ much more rapidly in the presence of $\mathrm{KBH}_{4}$. In particular, $\mathrm{Ag} / \mathrm{Au}$ nanocomposites fabricated at $85^{\circ} \mathrm{C}$ show the most efficient catalytic performance as they have the largest nanocavities, which are surrounded by the most porous walls. The high enhancement of the catalytic performance is attributed to the facilitation of rapid electron relay from $\mathrm{BH}_{4}{ }^{-}$to rhodamine $\mathrm{B}$ via the catalytic surface, consequently lowering the kinetic barrier of the catalytic reaction. Overall, the temperature of the galvanic replacement reaction has been varied to optimize the morphology and the subsequent catalytic performance of Ag/Au nanocomposites.
\end{abstract}

\section{Introduction}

Metallic nanostructured materials have received a great deal of research effort owing to their outstanding physical and chemical properties depending on size, shape, and composition..$^{1-3}$ In particular, there has been a growing interest in nanostructures comprising noble metals due to their unusual physicochemical characteristics which are considerably distinct from their bulksized analogues. ${ }^{4,5}$ In this respect, the fabrication of nanometersized noble metals has led to intriguing applications in various fields such as photography, spectroscopy, optoelectronics, sensing, biological labeling, and catalysis. ${ }^{6-8}$ Bimetallic nanostructures consisting of noble metals such as silver, gold, palladium and platinum have received special attention because their unique optical, electronic, and catalytic properties, which lead to a broad range of applications, including localized surface-plasmon resonance, surface-enhanced Raman scattering, biosensing, and catalysis., ${ }^{\mathbf{9 1 0}}$ For example, by combining $\mathrm{Ag}$ and $\mathrm{Au}$ into a single entity, catalytic properties can be further improved and localized surface-plasmon absorption can be varied continuously to the limits of the corresponding monometallic particles. ${ }^{\mathbf{1 1}, 12}$ Diverse approaches to synthesize the bimetallic nanomaterials have been studied: the

Department of Chemistry, Seoul National University, NS60, Seoul 08826, Korea. E-mail:djjang@snu.ac.kr

$\uparrow$ Electronic supplementary information (ESI) available: Supplementary figures (Fig. S1-S10). See DOI: 10.1039/c6ra26249j simultaneous chemical reduction of mixed metal ions, the electrochemical reduction, and the galvanic replacement reaction on the surface of sacrificial nanoparticles. ${ }^{13,14}$

The galvanic replacement reaction is basically a redox process between two metals with distinct reduction potentials. Oxidation takes place in one metal with a low reduction potential which is referred to as a sacrificial template, and reduction coincides with the deposition of the other metal with a high reduction potential. ${ }^{15-17}$ This simple process is controlled solely by a favorable difference between the reduction potentials of two metals. The galvanic exchange provides a simple and flexible route to engineering a range of advanced multifunctional nanostructures such as hollow cavities and porous walls. ${ }^{\mathbf{1 4 , 1 8 , 1 9}}$ Among various noble metal-based nanostructures, hollow architectures are a particularly interesting class of materials that have unusual chemical and physical properties compared to the respective ones of solid counterparts. ${ }^{20-22}$ The galvanic replacement process has been employed as a useful method for preparing hollow metallic composite nanostructures including spherical nanoshells, nanodendrites, nanoboxes, nanocages, nanotubes, and nanoframes consisting of $\mathrm{Au}, \mathrm{Pd}$, and/or Pt by using $\mathrm{Ag}, \mathrm{Cu}$, or more reactive metals as sacrificial templates. ${ }^{23-25}$ These hollow metallic composite nanostructures have a great deal of promise for diverse fields including photothermal therapy, biomedical imaging, drug delivery, and electrochemical catalysis. In particular, catalytic performances can be optimized by controlling surface compositions, sizes, and morphologies carefully. ${ }^{14,25,26}$ Hollow- 


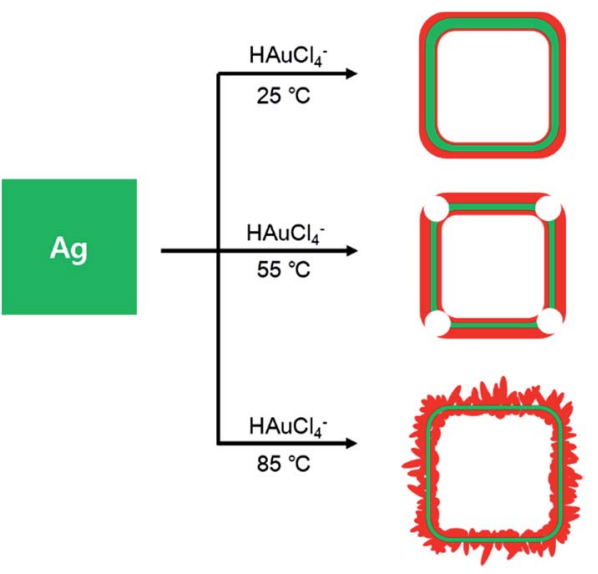

Fig. 1 Illustration for the temperature-controlled morphology evolution of $\mathrm{Ag} / \mathrm{Au}$ nanocomposites.

structured $\mathrm{Ag} / \mathrm{Au}$ nanocomposites exhibit high catalytic activity as they have high surface-to-volume ratios, low densities, and two different types of surfaces, which are the interior and the exterior walls of hollow nanostructures.

Herein, we have controlled the morphologies of Ag/Au nanocomposites via modified galvanic replacement reactions involving Ag nanocubes as sacrificial templates; the variation of reaction temperatures has resulted in the nanostructure modification of $\mathrm{Ag} / \mathrm{Au}$ nanocomposites. Whereas $\mathrm{Ag} / \mathrm{Au}$ nanocomposites prepared at 25 and $55{ }^{\circ} \mathrm{C}$ look like nanoboxes and truncated nanoboxes, respectively, $\mathrm{Ag} / \mathrm{Au}$ nanocomposites fabricated at $85{ }^{\circ} \mathrm{C}$ resemble porous nanoboxes, as shown in Fig. 1. The catalytic activities of $\mathrm{Ag} / \mathrm{Au}$ nanocomposites prepared at various reaction temperatures have been investigated by measuring the catalytic reduction rate constants and other kinetic parameters of rhodamine $\mathrm{B}(\mathrm{RhB})$ in the presence of $\mathrm{BH}_{4}{ }^{-}$. It has been found that the catalytic rate constant via $\mathrm{Ag} / \mathrm{Au}$ nanocomposites prepared at $85^{\circ} \mathrm{C}$ is higher by factors of $2.2,1.5$, and 100 than the rate constants of $\mathrm{Ag} / \mathrm{Au}$ nanocomposites prepared at 25,55 , and $105{ }^{\circ} \mathrm{C}$, respectively. This indicates that we can control the morphologies of $\mathrm{Ag} / \mathrm{Au}$ nanocomposites to enhance their catalytic performances readily by adjusting the temperatures of galvanic replacement reactions.

\section{Experimental section}

\section{Materials}

Chemicals were used as purchased without further purification: $\mathrm{HAuCl}_{4} \cdot 3 \mathrm{H}_{2} \mathrm{O}$ (s, $\geq 99.9 \%$ ), $\mathrm{CF}_{3} \mathrm{COOAg}$ (s, $\geq 99.9 \%$ ), polyvinylpyrrolidone (PVP, s, MW $=55000), \mathrm{Na}_{2} \mathrm{~S} \cdot 9 \mathrm{H}_{2} \mathrm{O}(\mathrm{s}$, $\geq 99.9 \%$ ), $37 \% \mathrm{HCl}(\mathrm{aq})$, and $\mathrm{KBH}_{4}$ (s, $\geq 95 \%$ ) from SigmaAldrich; ethylene glycol (EG, 1, 99\%) from Daejung Chemicals; rhodamine B (RhB, s) from Wako Chemicals. Deionized water (>15 M $\Omega \mathrm{cm}$ ) from an Elga PURELAB Option-S system was used throughout the experiments.

\section{Synthesis of $\mathrm{Ag}$ nanocubes}

Pristine Ag nanocubes (Ag(pr)) were synthesized via a sulfidemediated polyol process, with EG as the solvent and
$\mathrm{CF}_{3} \mathrm{COOAg}$ as a precursor of elemental silver. ${ }^{21,22,27}$ In a typical synthesis, $20 \mathrm{~mL}$ of EG was added into a $100 \mathrm{~mL}$ round-bottom flask and heated in an oil bath at $160{ }^{\circ} \mathrm{C}$ for $30 \mathrm{~min}$ under magnetic stirring to remove residual water. $0.24 \mathrm{~mL}$ of $3.0 \mathrm{mM}$ $\mathrm{Na}_{2} \mathrm{~S} \cdot 9 \mathrm{H}_{2} \mathrm{O}$ (EG) was then injected quickly into the preheated EG. After $2 \mathrm{~min}, 2.0 \mathrm{~mL}$ of $3.0 \mathrm{mM} \mathrm{HCl}(\mathrm{EG})$ and $5.0 \mathrm{~mL}$ of $20 \mathrm{mg}$ $\mathrm{mL}^{-1}$ PVP(EG) were quickly injected into the mixture. After additional $2 \mathrm{~min}, 1.6 \mathrm{~mL}$ of $282 \mathrm{mM} \mathrm{CF}_{3} \mathrm{COOAg}$ (EG) was added into the mixture, which was then reacted for $20 \mathrm{~min}$ at $160{ }^{\circ} \mathrm{C}$. During the entire reaction, the flask was capped with a rubber stopper except for the injection of reagents. The reaction mixture was quenched by placing the flask in an ice-water bath and added with acetone. The produced colloid was centrifuged, rinsed once with acetone and three times with water to remove remaining EG and PVP, and re-dispersed in water, yielding an aqueous colloidal solution of $\mathrm{Ag}(\mathrm{pr})$.

\section{Preparation of $\mathrm{Ag} / \mathrm{Au}$ nanocomposites}

$\mathrm{Ag} / \mathrm{Au}$ nanocomposites were prepared via galvanic replacement reactions between $\mathrm{Ag}(\mathrm{pr})$ and $\mathrm{HAuCl}_{4}$ in water. $0.30 \mathrm{~mL}$ of the $\mathrm{Ag}(\mathrm{pr})$ colloid was dispersed in $5.0 \mathrm{~mL}$ of $1.0 \mathrm{mg} \mathrm{mL}^{-1} \mathrm{PVP}(\mathrm{aq})$ and heated to a specific reaction temperature. $1.0 \mathrm{~mL}$ of $0.50 \mathrm{mM} \mathrm{HAuCl}$ (aq) was then added into the mixture, which was maintained for $20 \mathrm{~min}$ at the temperature. The produced $\mathrm{Ag} / \mathrm{Au}$ nanocomposites were centrifuged, rinsed with water three times, and then dispersed in water. To adjust the morphology of $\mathrm{Ag} / \mathrm{Au}$ nanocomposites, the temperatures of galvanic replacement reactions were varied from 0 to $105{ }^{\circ} \mathrm{C}$; hereafter, $\mathrm{Ag} / \mathrm{Au}$ nanocomposites prepared at 0, 25, 55, 85, and $105{ }^{\circ} \mathrm{C}$ will be described as $\mathrm{Ag} / \mathrm{Au}(0), \mathrm{Ag} / \mathrm{Au}(25), \mathrm{Ag} / \mathrm{Au}(55), \mathrm{Ag} /$ $\mathrm{Au}(85)$, and $\mathrm{Ag} / \mathrm{Au}(105)$, respectively.

\section{Characterization}

The samples for transmission electron microscopy (TEM) were prepared by dropping the aqueous colloidal solution of nanocatalysts onto a carbon-coated $\mathrm{Cu}$ grid. Whereas TEM images were taken using a Hitachi H-7600 microscope operated at 80 $\mathrm{kV}$, energy-dispersive X-ray (EDX) elemental profiles and maps, as well as scanning transmission electron microscopy (STEM) images, were measured using a JEOL JEM-2100F microscope operated at $200 \mathrm{kV}$. UV-visible absorption spectra were recorded using a Scinco S-3100 spectrometer with a temperature controller.

\section{Measurement of catalytic properties}

The catalytic performances of $\mathrm{Ag} / \mathrm{Au}$ nanocomposites were investigated by measuring the reduction reaction of $\mathrm{RhB}$ in $\mathrm{BH}_{4}{ }^{-}$(aq). $0.10 \mathrm{~mL}$ of a nanocatalyst colloid was added to 0.90 $\mathrm{mL}$ of water and $1.7 \mathrm{~mL}$ of $20 \mu \mathrm{M} \mathrm{RhB}(\mathrm{aq})$ contained in a quartz cuvette having a path length of $10 \mathrm{~mm}$. The absorption changes of $\mathrm{RhB}(\mathrm{aq})$ were confirmed using the above described temperature-controllable spectrometer at scheduled intervals after addition of $0.40 \mathrm{~mL}$ of $10 \mathrm{mM} \mathrm{KBH}_{4}(\mathrm{aq})$. Note that the concentrations of $\mathrm{Ag}$ and $\mathrm{Au}$, calculated based on the respective precursor amounts, in a cuvette of catalysis experiments were 20 and $8.1 \mu \mathrm{M}$, respectively. The catalytic activity was also 
investigated by measuring the reduction reaction of 4-nitrophenol (4-NP) into 4-aminophenol (4-AP); the experimental procedure was the same except that $1.7 \mathrm{~mL}$ of $20 \mu \mathrm{M} \mathrm{RhB}(\mathrm{aq})$, $0.90 \mathrm{~mL}$ of water, and $0.40 \mathrm{~mL}$ of $10 \mathrm{mM} \mathrm{KBH}_{4}(\mathrm{aq})$ were replaced by $50 \mu \mathrm{L}$ of $2.0 \mathrm{mM} 4-\mathrm{NP}(\mathrm{s}, \geq 99 \%$, purchased from Sigma-Aldrich), $2.25 \mathrm{~mL}$ of water, and $0.6 \mathrm{~mL}$ of $10 \mathrm{mM}$ $\mathrm{KBH}_{4}(\mathrm{aq})$. In order to investigate the reusability of the nanocatalysts, all the experimental parameters were kept constant. The used nanocatalysts were separated from the mixture solution by centrifugation at $13000 \mathrm{rpm}$, rinsed with water, and redispersed into water for the next cycle of catalysis. Then, the same processes were repeated three times under the same conditions.

\section{Results and discussion}

\section{TEM characterization}

Fig. 2 and $\mathrm{S} 1 \dagger$ indicate that the evolution of different morphologies of $\mathrm{Ag} / \mathrm{Au}$ nanocomposites has been induced by varying the temperatures of $\mathrm{Ag}$ templates-engaged galvanic replacement reactions. Truncated nanocubes of $\mathrm{Ag}(\mathrm{pr})$ (Fig. 2a) with an average edge length of $43.1 \pm 5.1 \mathrm{~nm}$ (Fig. S2a $\dagger$ ) were prepared for sacrificial nanotemplates via a typical sulfidemediated polyol procedure. ${ }^{21,22,27}$ As $\mathrm{Ag}(\mathrm{pr})$ was mixed with $\mathrm{HAuCl}_{4}(\mathrm{aq})$, the galvanic replacement reaction took place immediately at the sites of the highest surface energy including defects, steps, or stacking faults. ${ }^{18}$ Thus, Ag atoms were oxidized to dissolve into the aqueous solution, producing small holes on the surfaces of nanocubes. Concurrently, Au ions were reduced to become $\mathrm{Au}$ atoms. Since $\mathrm{Ag}$ and $\mathrm{Au}$ have the same facecentered cubic structure and similar lattice constants, $\mathrm{Au}$ atoms are prone to be epitaxially deposited on Ag surfaces, forming an incomplete thin layer. ${ }^{17,18}$ Small holes formed in the $\mathrm{Au}$ layer act as primary sites for the continuous dissolution of $\mathrm{Ag}$. As a result, $\mathrm{Ag}(\mathrm{pr})$ templates were partially dissolved to produce a cavity inside each nanoparticle. The temperature at which the galvanic replacement reaction takes place plays an important role in the formation of $\mathrm{Ag} / \mathrm{Au}$ nanocomposites since

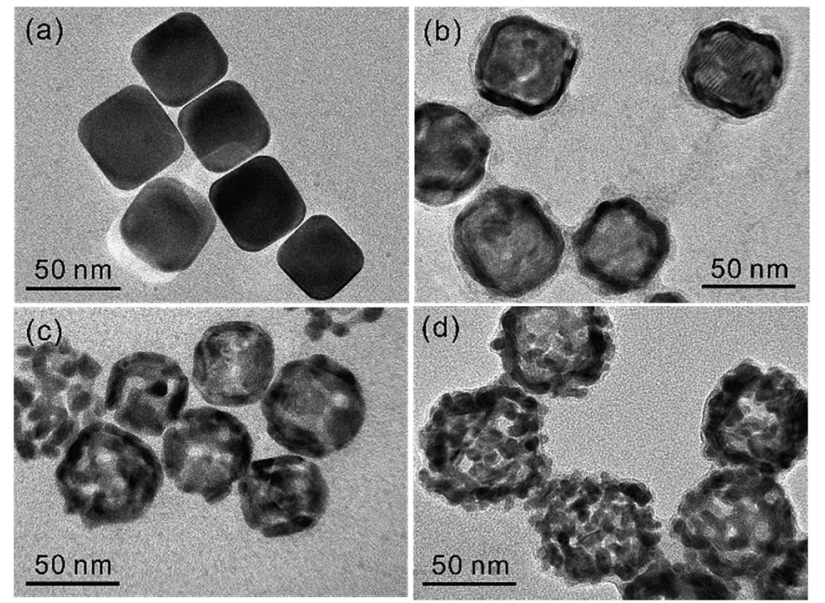

Fig. 2 TEM images of (a) Ag(pr), (b) Ag/Au(25), (c) $\mathrm{Ag} / \mathrm{Au}$ (55) and (d) Ag/ $\mathrm{Au}(85)$. the rate of the galvanic replacement reaction increases exponentially with temperature. Fig. S2 $\uparrow$ shows that the observed mean edge lengths of $\mathrm{Ag} / \mathrm{Au}(0), \mathrm{Ag} / \mathrm{Au}(25), \mathrm{Ag} / \mathrm{Au}(55), \mathrm{Ag} / \mathrm{Au}(85)$, and $\mathrm{Ag} / \mathrm{Au}(105)$ are $48.7 \pm 10.8,46.6 \pm 4.8,46.9 \pm 5.3,49.8 \pm$ 7.2 , and $47.5 \pm 7.1 \mathrm{~nm}$, respectively, supporting that reduced $\mathrm{Au}$ atoms have been deposited on the exterior surfaces of $\mathrm{Ag}$ nanotemplates. Fig. 2 and S1 $\uparrow$ indicate that the structures of Ag/ $\mathrm{Au}(0), \mathrm{Ag} / \mathrm{Au}(25), \mathrm{Ag} / \mathrm{Au}(55), \mathrm{Ag} / \mathrm{Au}(85)$, and $\mathrm{Ag} / \mathrm{Au}(105)$ are $\mathrm{Au}-$ decorated $\mathrm{Ag}$ nanocubes, well-defined nanoboxes, truncated nanoboxes, and porous nanoboxes, and amorphous nanocomposites, respectively. The hollow interiors of $\mathrm{Ag} / \mathrm{Au}$ nanocomposites have been found in $\mathrm{Ag} / \mathrm{Au}(25), \mathrm{Ag} / \mathrm{Au}(55)$, and $\mathrm{Ag} /$ $\mathrm{Au}(85)$; the average cavity sizes of $\mathrm{Ag} / \mathrm{Au}(25), \mathrm{Ag} / \mathrm{Au}(55)$, and $\mathrm{Ag} / \mathrm{Au}(85)$ have been estimated as 29.8, 33.4, and $39.3 \mathrm{~nm}$, respectively. The roughness and porosity of nanoboxes also increase with the increase of the reaction temperature. Thus, nanoboxes of $\mathrm{Ag} / \mathrm{Au}(85)$ have the largest cavities surrounded by the roughest and the most porous walls among our prepared Ag/ $\mathrm{Au}$ nanocomposites. Note that nanobox structures having hollow interiors were not formed when the temperature was too low as $0{ }^{\circ} \mathrm{C}$ or too high as $105{ }^{\circ} \mathrm{C}$. Overall, Fig. 2, S1, and $\mathrm{S} 2 \dagger$ indicate the morphologies of $\mathrm{Ag} / \mathrm{Au}$ nanocomposites have been controlled facilely by adjusting the temperatures of galvanic replacement reactions.

\section{EDX and STEM analysis}

The EDX line-scanned elemental profiles have been explored to confirm the elemental distributions and exact structures of Ag/ $\mathrm{Au}$ nanocomposites. Fig. 3a reveals that $\mathrm{Ag}(\mathrm{pr})$ is a solid $\mathrm{Ag}$ nanocube with an edge size of $45.3 \mathrm{~nm}$. Meanwhile, the linescanned EDX elemental profiles of $\mathrm{Ag} / \mathrm{Au}(25)$ (Fig. 3b), $\mathrm{Ag} /$ $\mathrm{Au}(55)$ (Fig. 3c), and $\mathrm{Ag} / \mathrm{Au}(85)$ (Fig. 3d) show that two characteristic sharp peaks of $\mathrm{Au}$ are similar to the respective ones of $\mathrm{Ag}$, indicating that the walls of a nanobox compositely consist of $\mathrm{Ag}$ and $\mathrm{Au}$. The elemental profiles also exhibit that the Ag edge sizes of $\mathrm{Ag} / \mathrm{Au}(0)$ (Fig. $\mathrm{S} 3 \dagger$ ), $\mathrm{Ag} / \mathrm{Au}(25), \mathrm{Ag} / \mathrm{Au}(55)$, and $\mathrm{Ag} / \mathrm{Au}(85)$ are $31.2,48.5,45.8$, and $49.1 \mathrm{~nm}$, respectively, whereas the $\mathrm{Au}$ edge sizes of $\mathrm{Ag} / \mathrm{Au}(0), \mathrm{Ag} / \mathrm{Au}(25), \mathrm{Ag} / \mathrm{Au}(55)$, and $\mathrm{Ag} / \mathrm{Au}(85)$ are 47.1, 50.1, 46.1, and $49.2 \mathrm{~nm}$, respectively. Thus, the Au edge size is larger than the $\mathrm{Ag}$ edge size in each examined $\mathrm{Ag} / \mathrm{Au}$ nanocomposite, indicating that reduced $\mathrm{Au}$ atoms deposit on the exterior surfaces of Ag nanotemplates preferentially. As the reaction temperature increases, the mobility of atoms can be promoted rapidly by heat so that atomic exchange between $\mathrm{Ag}$ cores and Au shells takes place rapidly to form $\mathrm{Ag} / \mathrm{Au}$ nanoalloys gradually. The STEM images and EDX elemental maps of Fig. 3 and $\mathrm{S} 3 \dagger$ also support that $\mathrm{Ag} / \mathrm{Au}(0), \mathrm{Ag} / \mathrm{Au}(25), \mathrm{Ag} / \mathrm{Au}(55)$, and $\mathrm{Ag} / \mathrm{Au}(85)$ have nanostructures of Au-decorated $\mathrm{Ag}$ nanocubes, well-defined nanoboxes, truncated nanoboxes, and porous nanoboxes.

\section{Absorption spectra}

Variation in the surface-plasmon resonance (SPR) spectra of $\mathrm{Ag}(\mathrm{pr}) . \mathrm{Ag} / \mathrm{Au}(25), \mathrm{Ag} / \mathrm{Au}(55)$, and $\mathrm{Ag} / \mathrm{Au}(85)$ depicted in Fig. 4 agrees well with the variation of morphologies, sizes, and compositions observed Fig. 2 and 3. The SPR spectrum of Ag(pr) 

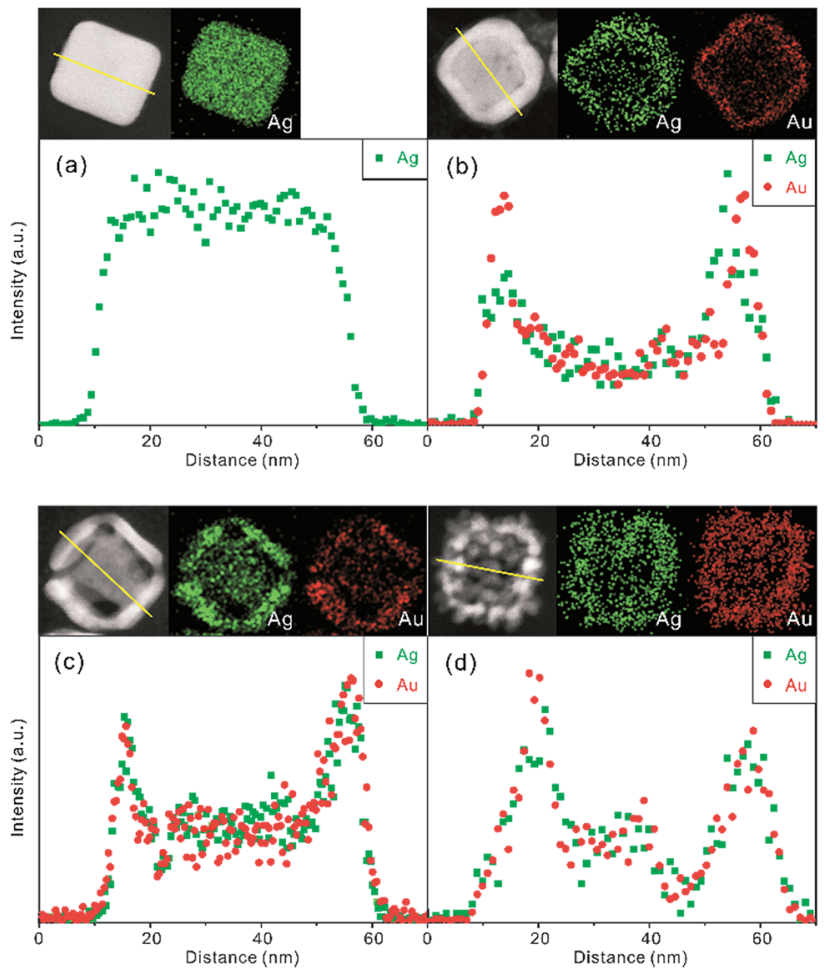

Fig. 3 STEM images, EDX elemental maps and area normalized linescanned profiles of (a) $\mathrm{Ag}(\mathrm{pr}),(\mathrm{b}) \mathrm{Ag} / \mathrm{Au}$ (25), (c) $\mathrm{Ag} / \mathrm{Au}$ (55) and (d) $\mathrm{Ag} /$ $\mathrm{Au}(85)$.

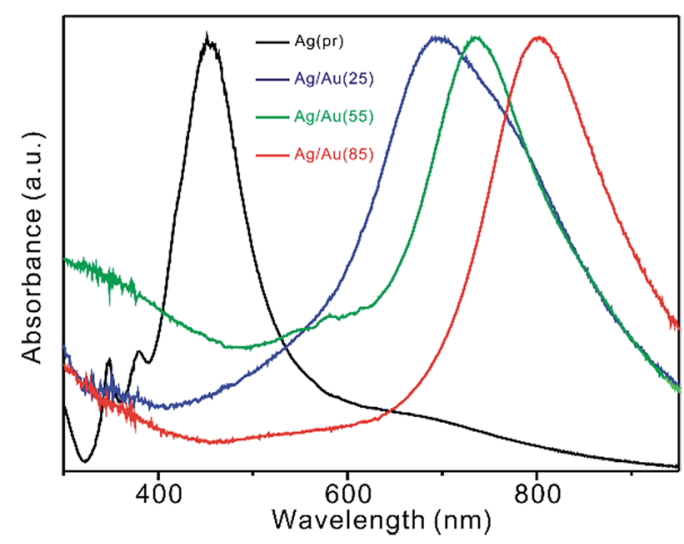

Fig. 4 Maximum-normalized surface-plasmon resonance spectra of indicated nanocatalysts in water.

shows three characteristic peaks of Ag nanocubes with an average edge size of $43.1 \pm 5.1 \mathrm{~nm}$, including the major SPR peak at $456 \pm 33 \mathrm{~nm}$. Meanwhile, the SPR spectra of $\mathrm{Ag} / \mathrm{Au}(25)$, $\mathrm{Ag} / \mathrm{Au}(55)$, and $\mathrm{Ag} / \mathrm{Au}(85)$ have the absorption maxima at $693 \pm$ $102,735 \pm 62$, and $802 \pm 77 \mathrm{~nm}$, respectively, indicating that the average length-to-thickness value for the walls of $\mathrm{Ag} / \mathrm{Au}$ nanoboxes increases with the increase of the reaction temperature. ${ }^{28-30}$ As shown in Fig. S1, S2, and S3, $\dagger$ the SPR spectra of Fig. S4 $\uparrow$ also suggest that Au nanoplates and elliptical nanoparticles have been deposited on the surfaces of $\mathrm{Ag}$ nanotemplates for $\mathrm{Ag} / \mathrm{Au}(0)$ while $\mathrm{Ag} / \mathrm{Au}$ broken nanoboxes consisting of numerous thin nanoplates and nanodiscs with diverse sizes have been produced for $\mathrm{Ag} / \mathrm{Au}(105)$.

\section{Catalytic performances}

The catalytic performances of $\mathrm{Ag} / \mathrm{Au}$ nanocomposites have been evaluated by measuring the time-dependent absorption spectra of $\mathrm{RhB}$ reduced catalytically by as-prepared $\mathrm{Ag} / \mathrm{Au}$ nanocomposites in the presence of $\mathrm{BH}_{4}{ }^{-}$as shown in Fig. 5 and $\mathrm{S} 5, \dagger$ indicating that the catalytic activity of $\mathrm{Ag} / \mathrm{Au}$ nanocomposites depends highly on their morphologies, ${ }^{26,30,31}$ which have been varied by adjusting the temperature of the galvanic replacement reaction. $\mathrm{RhB}$, which consists of a central xanthene ring connected to four $N$-ethyl groups, two on each side, exhibits high resistance to photodegradation..$^{32,33}$ Thus, the rapid reduction of $\mathrm{RhB}$ is important in regard to the purification of dye effluents. The residual concentration of $\mathrm{RhB}$ reduced catalytically via $\mathrm{Ag} /$ $\mathrm{Au}$ nanocomposites in the presence of $\mathrm{KBH}_{4}$ at a specific time has been estimated by monitoring the optical density of $\mathrm{RhB}$ at $554 \mathrm{~nm}$. Fig. 5 and $\mathrm{S} 5 \dagger$ show that $\mathrm{Ag} / \mathrm{Au}$ nanocomposites have much higher catalytic activities than $\mathrm{Ag}(\mathrm{pr})$; whereas only $2 \%$ has been reduced in $40 \mathrm{~min}$ in the presence of $\mathrm{Ag}(\mathrm{pr}), 70,35,49$, 97 and $9 \%$ of $\mathrm{RhB}$ have been reduced within $40 \mathrm{~min}$ in the presence of $\mathrm{Ag} / \mathrm{Au}(0), \mathrm{Ag} / \mathrm{Au}(25), \mathrm{Ag} / \mathrm{Au}(55), \mathrm{Ag} / \mathrm{Au}(85)$, and $\mathrm{Ag} /$ $\mathrm{Au}(105)$, respectively. This also indicates that the catalytic activity is dependent strongly on the structures of $\mathrm{Ag} / \mathrm{Au}$ nanocomposites. In particular, $\mathrm{Ag} / \mathrm{Au}(85)$ having the largest cavities surrounded by the most porous walls has shown the most efficient catalytic performance.

Fig. 6 and $56 \dagger$ show that the time-dependent pseudo-firstorder reduction profiles of $\mathrm{RhB}$ catalyzed by $\mathrm{Ag}(\mathrm{pr}), \mathrm{Ag} / \mathrm{Au}(25)$, $\mathrm{Ag} / \mathrm{Au}(55)$, and $\mathrm{Ag} / \mathrm{Au}(85)$ in the presence of $\mathrm{KBH}_{4}$ have been used to elicit observed reduction constants $\left(k_{\mathrm{obs}}\right)$; the plots of $\ln \left(A / A_{0}\right)=-k_{\mathrm{obs}} t,,^{20,33}$ where $A$ and $A_{0}$ are the optical densities of $\mathrm{RhB}$ at $554 \mathrm{~nm}$ at times $t$ and 0 , respectively, have been used to extract $k_{\text {obs }}$ presented in Table 1 . The rate constant of a $\mathrm{Ag} / \mathrm{Au}$ nanocomposite catalyst $(k)$ has been extracted by deducting

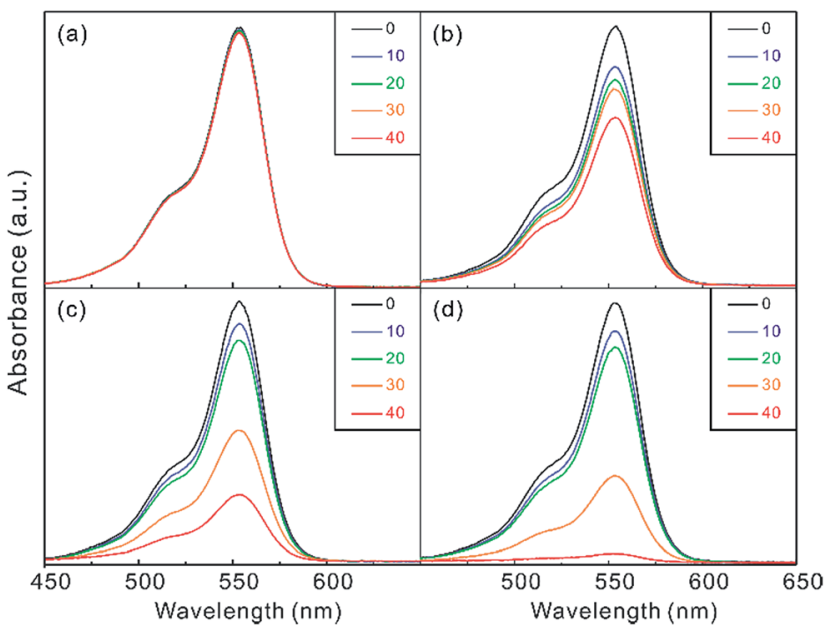

Fig. 5 Absorption spectra at $25^{\circ} \mathrm{C}$ of $11 \mu \mathrm{M} \mathrm{RhB}(\mathrm{aq})$ in the presence of $1.3 \mathrm{mM} \mathrm{KBH}_{4}$, monitored at indicated times in the units of min after addition of (a) $\mathrm{Ag}$ (pr), (b) $\mathrm{Ag} / \mathrm{Au}$ (25), (c) $\mathrm{Ag} / \mathrm{Au}$ (55) and (d) $\mathrm{Ag} / \mathrm{Au}$ (85). 

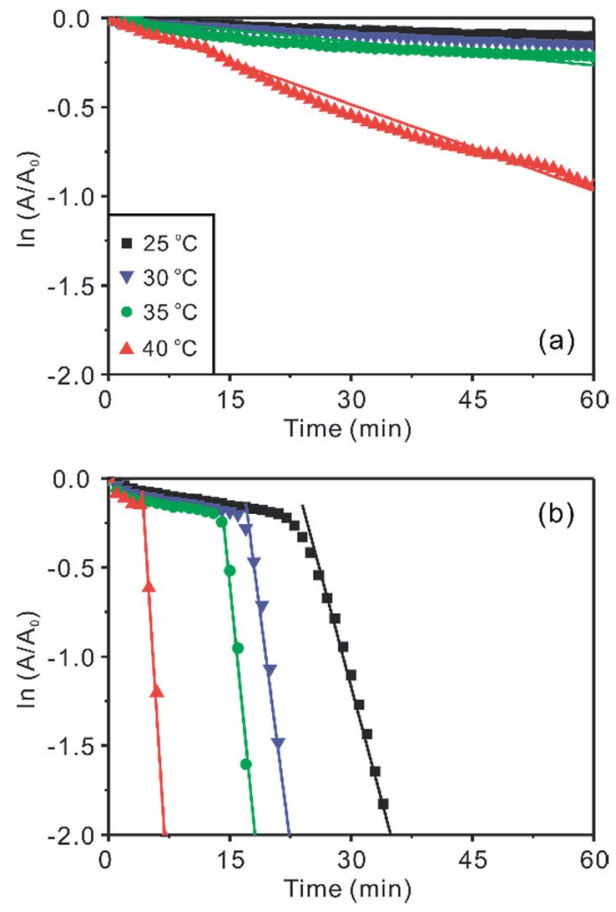

Fig. $6 \ln \left(A / A_{0}\right)$ vs. $t$ for the catalytic reduction of $11 \mu \mathrm{M} \mathrm{RhB(aq)} \mathrm{via} \mathrm{(a)}$ $\mathrm{Ag}\left(\mathrm{pr}\right.$ ) (b) $\mathrm{Ag} / \mathrm{Au}(85)$ in the presence of $1.3 \mathrm{mM} \mathrm{KBH}_{4}$ at indicated temperatures.

the reduction rate constant of $\mathrm{RhB}$ with no nanocatalysts $\left(k_{0}\right)$ from $k_{\mathrm{obs}} ; k=k_{\mathrm{obs}}-k_{0} \cdot{ }^{20,34}$ The catalytic rate constants of nanocatalysts conducted at four different reaction temperatures indicate that the catalytic performances of nanocatalysts increase rapidly with increment of temperature. Fig. 6 and Table 1 exhibit that a certain period of time was required for a certain $\mathrm{Ag} / \mathrm{Au}$ nanocatalyst to start catalysis. As observed in a number of systems, ${ }^{8,35-37}$ this period, defined as the induction time $\left(t_{0}\right)$, has been attributed to a slow diffusion of reactants onto the catalytic surfaces. Table 1 indicates that the induction time is necessary for $\mathrm{Ag} / \mathrm{Au}$ nanoboxes with hollow interiors, suggesting that the fast catalytic reduction of $\mathrm{RhB}$ molecules takes place in the cavities of $\mathrm{Ag} / \mathrm{Au}$ nanoboxes and that it takes $t_{0}$ for RhB to diffuse through the walls of the nanoboxes. Table 1 also suggests that $t_{0}$ decreases gradually as the walls of the nanoboxes become more porous. Meanwhile, none of $\mathrm{Ag}(\mathrm{pr})$, $\mathrm{Ag} / \mathrm{Au}(0)$, and $\mathrm{Ag} / \mathrm{Au}(105)$ show the induction time because none of them have hollow interiors. In addition, the reduction kinetic data of 4-NP into 4-AP in Fig. S7 $\uparrow$ also demonstrate clearly that the catalytic activity of $\mathrm{Ag} / \mathrm{Au}(85)\left(k=0.10 \mathrm{~min}^{-1}\right)$ is much higher than that of $\mathrm{Ag}(\mathrm{pr})\left(k=0.0013 \mathrm{~min}^{-1}\right)$. The catalytic reduction kinetic data and the induction times of 4-NP are almost consistent with the respective ones of RhB.

Fig. 7a shows that Arrhenius plots have been used to extract the activation energies $\left(E_{\mathrm{a}}\right)$ and frequency factors $(A)$ of $\mathrm{Ag}(\mathrm{pr})$ and $\mathrm{Ag} / \mathrm{Au}$ nanocatalysts. Table 1 indicates that $\mathrm{Ag} / \mathrm{Au}$ nanocatalysts with hollow interiors have much smaller $E_{\mathrm{a}}$ and $A$ values than nanocatalysts without cavities. As already discussed with Fig. 6, this observation also suggests that the catalysis reaction taking place in cavities is much faster than the reaction occurring at exterior surfaces as the confinement effect reduces the energy barrier. A close examination of Table 1 reveals that among $\mathrm{Ag} / \mathrm{Au}$ nanoboxes having hollow structures, in particular, $\mathrm{Ag} / \mathrm{Au}(85)$ has the smallest $E_{\mathrm{a}}$ value to show the highest catalytic activity because the $\mathrm{Ag} / \mathrm{Au}(85)$ nanocatalyst has the largest nanocavity surrounded by the most porous walls. In addition, Fig. $\mathrm{S} 8 \dagger$ also indicates that $\mathrm{Ag} / \mathrm{Au}$ nanocomposites have the different amount of $\mathrm{Au}$ atoms as the galvanic replacement has taken place at diverse temperatures, implying that with the increase of temperature, the more Au atoms have been reduced and deposited onto the surface of $\mathrm{Ag}(\mathrm{pr})$. Thus, the active sites to induce the catalytic reaction on $\mathrm{Ag} / \mathrm{Au}$ nanocomposites are quite different depending on the molar fraction of Au. With the increase of Au atoms, the catalytic efficiency was steadily enhanced ${ }^{21}$ since the $\mathrm{Au}$ has been known well to have better catalytic activity than Ag. ${ }^{38,39}$ Overall, the lowest activation energy for the catalytic reaction of $\mathrm{Ag} / \mathrm{Au}(85)$ nanocomposites is attributed to not only the largest amount of $\mathrm{Au}$ atoms but also the largest nanocavity, which finally contribute to the higher catalytic activity of the nanocomposites. Furthermore, the activation enthalpies $\left(\Delta H^{*}\right)$ and activation entropies $\left(\Delta S^{\ddagger}\right)$ listed in Table 1 have been elicited from Eyring plots in Fig. S6: $\dagger \ln (k /$ T) vs. $1 / T$ to exhibit $\ln (k / \mathrm{T})=-\Delta H^{\sharp} /(R T)+\Delta S^{\ddagger} / R+\ln \left(k_{\mathrm{B}} / h\right) \cdot^{34,40}$ Table 1 shows that not only $\Delta H^{\star}$ but also $\Delta S^{\ddagger}$ are smallest for Ag/ $\mathrm{Au}(85)$, suggesting that activated-complex formation for the catalytic reduction reaction of $\mathrm{RhB}$ via $\mathrm{Ag} / \mathrm{Au}(85)$ is most favorable in energy but most unfavorable in degree of freedom. This suggests that the most efficient catalytic performance and the smallest $E_{\text {a }}$ value of $\mathrm{Ag} / \mathrm{Au}(85)$ can be attributed to the energetically most favorable formation of the activated complex within the cavity of a $\mathrm{Ag} / \mathrm{Au}(85)$ nanobox. Overall, Fig. 7a and

Table 1 Observed rate constants $\left(k_{\text {obs }}\right)$ at $25^{\circ} \mathrm{C}$, induction time $\left(t_{0}\right)$ at $25^{\circ} \mathrm{C}$, activation energies $\left(E_{\mathrm{a}}\right)$, frequency factors $(A)$, activation enthalpies $\left(\Delta H^{\star}\right)$, and activation entropies $\left(\Delta S^{\ddagger}\right)$ for the catalytic reduction of RhB catalyzed by nanocomposites in $\mathrm{KBH}_{4}(\mathrm{aq})$

\begin{tabular}{llllllll}
\hline Catalyst & $d_{\mathrm{c}}{ }^{a}(\mathrm{~nm})$ & $k_{\mathrm{obs}}{ }^{b}\left(\mathrm{~min}^{-1}\right)$ & $t_{0}(\mathrm{~min})$ & $E_{\mathrm{a}}\left(\mathrm{kcal} \mathrm{mol}^{-1}\right)$ & $A\left(\mathrm{~min}^{-1}\right)$ & $\Delta H^{\ddagger}\left(\mathrm{kcal} \mathrm{mol}^{-1}\right)$ & $\Delta S^{\ddagger}\left(\mathrm{cal} \mathrm{mol}^{-1} \mathrm{~K}^{-1}\right)$ \\
\hline $\mathrm{Ag}(\mathrm{pr})$ & $-{ }^{c}$ & 0.0014 & 0 & 34.4 & $3.1 \times 10^{21}$ & 33.8 & 29.6 \\
$\mathrm{Ag} / \mathrm{Au}(0)$ & - & 0.035 & 0 & 28.0 & $1.2 \times 10^{19}$ & 27.4 & 18.5 \\
$\mathrm{Ag} / \mathrm{Au}(25)$ & 30 & 0.072 & 35 & 21.7 & $6.7 \times 10^{14}$ & 21.1 & -0.9 \\
$\mathrm{Ag} / \mathrm{Au}(55)$ & 33 & 0.11 & 27 & 19.6 & $2.3 \times 10^{13}$ & 19.0 & -7.2 \\
$\mathrm{Ag} / \mathrm{Au}(85)$ & 39 & 0.16 & 22 & 15.9 & $9.1 \times 10^{10}$ & 15.4 & -18.6 \\
$\mathrm{Ag} / \mathrm{Au}(105)$ & - & 0.0016 & 0 & 32.9 & $5.0 \times 10^{20}$ & 32.3 & 26.0
\end{tabular}

${ }^{a}$ Average cavity diameters estimated using HRTEM images. ${ }^{b}$ The value in the absence of any catalysts $\left(k_{0}\right)$ is 0.0012 min ${ }^{-1} \cdot{ }^{c}$ Not observed. 

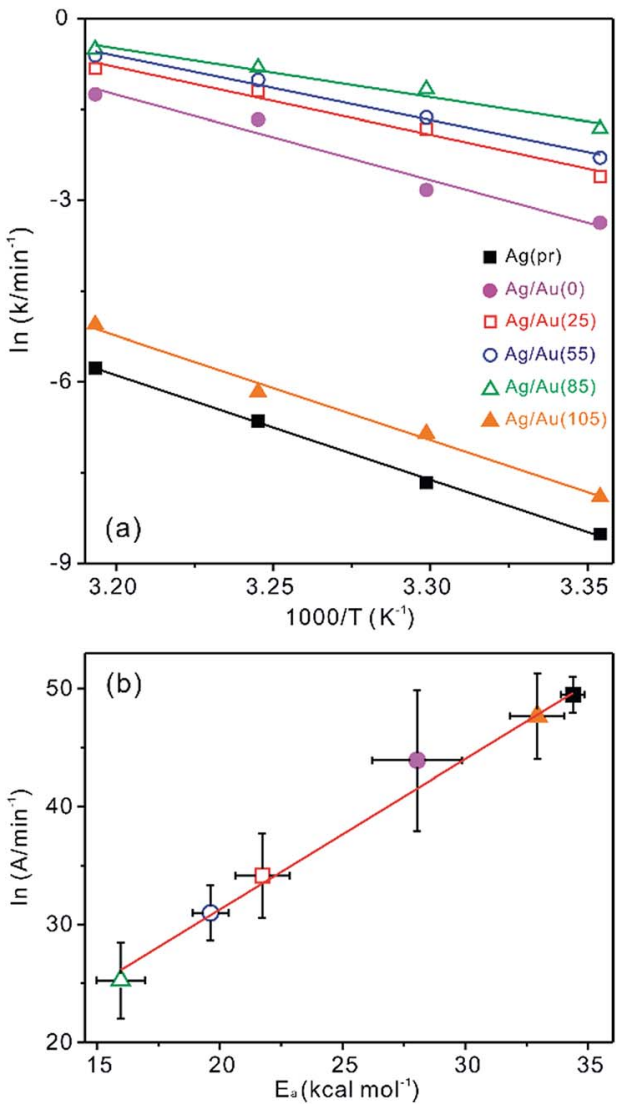

Fig. 7 (a) Arrhenius plots for the reduction reaction of $11 \mu \mathrm{M}$ RhB(aq) catalyzed by indicated nanocatalysts in $1.3 \mathrm{mM} \mathrm{KBH}_{4}(\mathrm{aq})$. (b) Compensation law plot of the frequency factors and the activation energies extracted from the Arrhenius plots.

Table 1 have revealed that the catalytic activity depends on the morphologies of $\mathrm{Ag} / \mathrm{Au}$ nanocomposites, which can be controlled by adjusting the galvanic replacement temperature. In particular, $\mathrm{Ag} / \mathrm{Au}(85)$ that has been fabricated at $85^{\circ} \mathrm{C}$ shows the most efficient catalytic performance.

Fig. 7b shows the compensation law plot of $\ln A=\alpha+E_{\mathrm{a}} /$ $\left(R T_{\theta}\right)$, where $\alpha$ is a constant and $T_{\theta}$ is the fictitious isokinetic temperature, where the catalytic rates of all the nanocomposites become the same. ${ }^{26,41,42}$ The empirical linear relationship between $\ln A$ and $E_{\mathrm{a}}$ of Fig. 7b clearly demonstrates the compensation effect in our catalytic system, where $T_{\theta}$ has been found as $395 \mathrm{~K}$. The compensation effect is relevant to a switching from a regime where the overall rate is controlled by the activation of the reactant to a regime where the stability of the product becomes more important. ${ }^{26,42}$ Thus, we consider that for the reaction with $\mathrm{Ag} / \mathrm{Au}$ nanoboxes having cavities, $E_{\mathrm{a}}$ was lower while the lower density of active sites would be compensated largely the stability of adsorption.

The catalytic reduction mechanism of RhB via nanocatalysts can be described as follows. The nucleophilic $\mathrm{BH}_{4}{ }^{-}$ions supply electrons to $\mathrm{Ag} / \mathrm{Au}$ nanocatalysts and then electrophilic $\mathrm{RhB}$ molecules adsorbed on Ag/Au nanocatalysts take electrons from $\mathrm{Ag} / \mathrm{Au}$ nanocatalysts, facilitating electron transfer from $\mathrm{BH}_{4}{ }^{-}$to $\mathrm{RhB}$ through their catalytic surfaces. ${ }^{20,31,34}$ Hence, $\mathrm{Ag} / \mathrm{Au}$ nanocatalysts act as electron relays for the reduction reaction of $\mathrm{RhB}$ in $\mathrm{KBH}_{4}(\mathrm{aq}) \cdot{ }^{\mathbf{8}, 31,34}$ With respect to the higher catalytic activity of $\mathrm{Ag} / \mathrm{Au}$ nanoboxes, the nanoreactor confinement effect of $\mathrm{Ag} / \mathrm{Au}$ nanocatalysts with hollow interiors is considered to expedite electron relays from $\mathrm{BH}_{4}{ }^{-}$to $\mathrm{RhB}$ enormously by reducing $E_{\mathrm{a}}$ extensively. Although catalytic stability during the reduction of RhB is an important factor, it is well-known that hollow structures have tendency to be unstable due to their high surface energy, resulting in the aggregation form as a stable state. $^{21,24}$ In order to check the stability of $\mathrm{Ag} / \mathrm{Au}(85)$ nanocatalyst, reusability tests have been conducted for three times. As shown in Fig. S10, $\uparrow$ the catalytic activity of our nanocatalyst has decreased significantly after repeated cycles of catalysis due to the intrinsically unstable nature of the hollow structure. We consider that although the catalytic activity of $\mathrm{Ag} / \mathrm{Au}(85)$ nanocomposites is considerably high, their stability is relatively low. Thus, we recognize that some ways to extend the limited reusability of nanocatalyst should be found to lower the overall price of noble-metal catalysts.

\section{Conclusions}

Morphology-controlled Ag/Au nanocomposite have been fabricated facilely via a modified galvanic replacement reaction using Ag nanocubes as sacrificial templates. The morphologies of $\mathrm{Ag} / \mathrm{Au}$ nanocomposites have been readily controlled by adjusting the temperature of the galvanic reaction; the structures of $\mathrm{Ag} / \mathrm{Au}$ nanocomposites prepared at 0, 25, 55, 85, and $105^{\circ} \mathrm{C}$ are $\mathrm{Au}$-decorated $\mathrm{Ag}$ nanocubes, well-defined nanoboxes, truncated nanoboxes, and porous nanoboxes, and broken nanoboxes, respectively. The catalytic activities of Ag nanocubes and $\mathrm{Ag} / \mathrm{Au}$ nanocomposites have been investigated by measuring the time-dependent reduction of $\mathrm{RhB}$ in the presence of $\mathrm{KBH}_{4} ; \mathrm{Ag} / \mathrm{Au}$ nanocomposites with hollow interiors have shown much higher catalytic activity with a smaller activation energy than pristine $\mathrm{Ag}$ nanocubes or $\mathrm{Ag} / \mathrm{Au}$ nanocomposites without cavities. Among $\mathrm{Ag} / \mathrm{Au}$ nanoboxes having hollow structures, $\mathrm{Ag} / \mathrm{Au}$ nanocomposites fabricated at $85{ }^{\circ} \mathrm{C}$ show the most efficient catalytic performances as their largest nanocavities are surrounded by the most porous walls. Regarding to the higher catalytic activity of $\mathrm{Ag} / \mathrm{Au}$ nanoboxes, the nanoreactor confinement effect of $\mathrm{Ag} / \mathrm{Au}$ nanocatalysts with hollow interiors is considered to expedite electron transfer from $\mathrm{KBH}_{4}$ to $\mathrm{RhB}$ enormously by reducing $E_{\mathrm{a}}$ largely; the energetically favorable formation of the activated complex within the cavities has lowered the energy barrier subsequently. Overall, the temperatures of galvanic replacement reactions have been varied to optimize the morphologies and the subsequent catalytic performances of $\mathrm{Ag} / \mathrm{Au}$ nanocomposites.

\section{Acknowledgements}

This work was supported by research grants through the National Research Foundation of Korea funded by the Korea government (2014-057382 and 2015-051798). 


\section{References}

1 G. Collins and J. D. Holmes, Adv. Mater., 2016, 28, 56895695.

2 M. Salerno, J. R. Krenn, B. Lamprecht, G. Schider, H. Ditlbacher, N. Felidj, A. Leitner and F. R. Aussenegg, Opto-Electron. Rev., 2002, 10, 217-224.

3 L. Wang and Y. Yamauchi, J. Am. Chem. Soc., 2013, 135, 16762-16765.

4 P. K. Jain, X. Huang, I. H. El-Sayed and M. A. El-Sayed, Acc. Chem. Res., 2008, 41, 1578-1586.

5 M. R. Langille, M. L. Personick, J. Zhang and C. A. Mirkin, J. Am. Chem. Soc., 2012, 134, 14542-14554.

6 Y. Yin, C. Erdonmez, S. Aloni and A. P. Alivisatos, J. Am. Chem. Soc., 2006, 128, 12671-12673.

7 Y. Sun, B. Wiley, Z.-Y. Li and Y. Xia, J. Am. Chem. Soc., 2004, 126, 9399-9406.

8 M. Son, J. Lee and D.-J. Jang, J. Mol. Catal. A: Chem., 2014, 385, 38-45.

9 S. Duan and R. Wang, Prog. Nat. Sci.: Mater. Int., 2013, 23, 113-126.

10 W. He, X. Wu, J. Liu, X. Hu, K. Zhang, S. Hou, W. Zhou and S. Xie, Chem. Mater., 2010, 22, 2988-2994.

11 Q. Zhang, J. Xie, J. Liang and J. Y. Lee, Adv. Funct. Mater., 2009, 19, 1387-1398.

12 P. Raveendran, J. Fu and S. L. Wallen, Green Chem., 2006, 8, 34-38.

13 X. Xia, Y. Wang, A. Ruditskiy and Y. Xia, Adv. Mater., 2013, 25, 6313-6333.

14 M. R. Kim, D. K. Lee and D.-J. Jang, Appl. Catal., B, 2011, 103, 253-260.

15 F. Bellucci, Corrosion, 1991, 47, 808-819.

16 C. Yang, Q. B. Zhang and A. P. Abbott, Electrochem. Commun., 2016, 70, 60-64.

17 E. González, J. Arbiol and V. F. Puntes, Science, 2011, 334, 1377-1380.

18 S. E. Skrabalak, J. Chen, Y. Sun, X. Lu, L. Au, C. M. Cobley and Y. Xia, Acc. Chem. Res., 2008, 41, 1587-1595.

19 X. Gong, Y. Yang and S. Huang, J. Phys. Chem. C, 2010, 114, 18073-18080.

20 J.-A. Kwak, D. K. Lee and D.-J. Jang, Appl. Catal., B, 2013, 142143, 323-328.

21 J. Lee, K. Han and D.-J. Jang, Appl. Catal., A, 2014, 469, 380386.
22 M. A. Mahmoud and M. A. El-Sayed, Langmuir, 2012, 28, 4051-4059.

23 H. Zhang, M. Jin, J. Wang, W. Li, P. H. C. Camargo, M. J. Kim, D. Yang, Z. Xie and Y. Xia, J. Am. Chem. Soc., 2011, 133, 60786089.

24 C. M. Kisukuri, D. J. Palmeira, T. S. Rodrigues, P. H. C. Camargo and L. H. Andrade, ChemCatChem, 2016, 8, 171-179.

25 X. Hong, D. Wang, S. Cai, H. Rong and Y. Li, J. Am. Chem. Soc., 2012, 134, 18165-18168.

26 J. Zeng, Q. Zhang, J. Chen and Y. Xia, Nano Lett., 2010, 10, 30-35.

27 Q. Zhang, W. Li, L.-P. Wen, J. Chen and Y. Xia, Chem.-Eur. J., 2010, 16, 10234-10239.

28 M. Hu, H. Petrova, A. R. Sekkinen, J. Chen, J. M. McLellan, Z.-Y. Li, M. Marguez, X. Li, Y. Xia and G. V. Hartland, J. Phys. Chem. B, 2006, 110, 19923-19928.

29 S. E. Skrabalak, L. Au, X. Li and Y. Xia, Nat. Protoc., 2007, 2, 2182-2190.

30 H. Wu, P. Wang, H. He and Y. Jin, Nano Res., 2012, 5, 135144.

31 J. Huang, S. Vongehr, S. Tang, H. Lu, J. Shen and X. Meng, Langmuir, 2009, 25, 11890-11896.

32 F. H. AlHamedi, M. A. Rauf and S. S. Ashraf, Desalination, 2009, 239, 159-166.

33 Y. Kim, H.-B. Kim and D.-J. Jang, J. Mater. Chem. A, 2014, 2, 5791-5799.

34 J. Lee and D.-J. Jang, J. Phys. Chem. C, 2016, 120, 4130-4138. 35 P. Hervés, M. Pérez-Lorénzo, L. M. Liz-Marzán, J. Dzubiella, Y. Lu and M. Ballauff, Chem. Soc. Rev., 2012, 41, 5577-5587.

36 M. A. Mahmoud and M. A. El-Sayed, Nano Lett., 2011, 11, 946-953.

37 S. Wunder, Y. Lu, M. Albrecht and M. Ballauff, ACS Catal., 2011, 1, 908-916.

38 W. Li, L. Kuai, L. Chen and B. Geng, Sci. Rep., 2013, 3, 2377. 39 R. Liu, J. Guo, G. Ma, P. Jiang, D. Zhang, D. Li, L. Chen, Y. Guo and G. Ge, ACS Appl. Mater. Interfaces, 2016, 8, 16833-16844.

40 K. D. Zimmer, R. Shoemaker and R. R. Ruminski, Inorg. Chim. Acta, 2006, 359, 1478-1484.

41 M. A. Mahmoud, F. Saira and M. A. El-Sayed, Nano Lett., 2010, 10, 3764-3769.

42 T. Bligaard, K. Honkala, A. Logadottir, J. K. Nørskov, S. Dahl and C. J. H. Jacobsen, J. Phys. Chem. B, 2003, 107, 9325-9331. 